\title{
Relationship between Anesthesia and Tumor: Can the Anesthesia affect the Prognosis of the Tumor?
}

\section{Zhou $\mathrm{Y}$, Zhang $\mathrm{H}$ and Wang $\mathbf{Q}^{*}$}

Department of Anesthesiology, Shanghai East Hospital, Tongji University School of Medicine, China

\begin{abstract}
Nowadays, cancer is still one of the most common reasons of death in the world. Surgery as the main treatment for some potentially treatable solid tumors. However, tumor metastasis is the most important cause of death in patients with these tumors. Clinical studies have found that surgery is an influence factor on tumor metastasis. In the perioperative period, the small residual lesions can be killed by the immune system, while it may also escape from the immune attack and then becoming the source of tumor metastasis and recurrence. Anesthesia covers the whole perioperative period, the effect on the patient's immune function mainly in the perioperative period. In recent years, the potential impact of anesthesia and some factors on the long-term prognosis of patients after resection of tumor has been paid more and more attention.
\end{abstract}

Keywords: Cancer; Cancer recurrence; General anesthesia; Anesthesia drugs; Immunosuppression

\section{Intravenous Anesthetics}

The literature has showed propofol can inhibit tumor cell invasion, proliferation and metastasis (mice showed that propofol play an anti-metastasis role in tumor) [1-10]. Propofol can also make cancer cell apoptosis in non-small cell lung cancer, colon cancer and ovarian [11]. The adhesion of propofol conjugates are inhibited the breast cancer cell migration and promoting apoptosis of cancer cells [12]. The present research showed that propofol may has less impact on the tumor metastasis mechanism and it had no obvious effect on the activity of NK cells but enhance the function of $\mathrm{T}$ cells in immune suppression effect during anesthesia. Propofol was found to inhibit hypoxia inducible factor in prostate cancer, so as to reduce stress damage during anesthesia $[13,14]$. Other studies have indicated that propofol can inhibit the function of neutrophils, monocytes and macrophages in the innate immune response, as well as the inhibition of B lymphocytes in critically ill patients $[15,16]$. The study also showed that propofol can increase the ratio of Thl/Th2 in PBMCs, it maintain the cell-mediated immune effect, which is beneficial for patients with immune dysfunction.

In a rat experimental, thiopentone and ketamine can promote the growth of implanted tumor cells and inhibit the activity of NK cells. However, propofol has played the protective effect. Ketamine mostly used in pediatric anesthesia, in vitro studies have found that ketamine can suppress neutrophil adhesion molecules on the surface and the production of oxygen free radicals, inhibit monocytes catalysis and through the mitochondrial pathway induced apoptosis of T lymphocytes $[17,18]$. Research about midazolam on tumor prognosis is not many, and that have no reference significance here.

\section{Opioid Drugs}

During the perioperative period, opioid drugs can affect the activity of NK cells and macrophages, inhibit the production of immune factors, so as to play a role in inhibiting immune defense function and promoting tumor recurrence and migration $[19,20]$. Opioids also play a role in the treatment of chronic pain. Opioid antagonist naloxone can inhibit NK cytotoxicity, lymphocyte proliferation, reduces the INF-r that caused by lower abdominal surgery which means cell immunosuppression and opioid peptides and their receptors are closely related. Studies have showed that fentanyl inhibits the immune func- tion of the body by inhibiting the activity of NK cells and be related to the dose [21]. Morphine can inhibit the apoptosis of breast cancer cells $[22,23]$. In a study showed that morphine and tramadol can inhibit $\mathrm{T}$ lymphocyte proliferation, but morphine showed persistent inhibition effect [24]. Morphine did not affect the activity of NK cells, and tramadol can increase inhibit the activity of NK cells [25]. Rats founded that tramadol can inhibit blocking surgical tumor metastasis and enhanced NK cell activity. However, comparative studies have suggested that certain opioids may be less immunoactive with less potential adverse effects on cancer immunosurveillance [26].

\section{Inhaled Anesthetics}

Inhalation anesthesia drugs (halothane, enflurane, isoflurane, sevoflurane) can inhibit the NK cells activity and reduced adhesion of neutrophils to endothelial cells and inhibition of lymphocyte proliferation [27]. Reducing the adhesion of neutrophils to endothelial cells and inhibiting the proliferation of lymphocytes. At the same time, inhaled anesthetics can inhibit the release of cytokines from peripheral blood mononuclear cells (PBMC), thereby inhibiting the inflammatory reaction [28]. The research showed that isoflurane can reduce the phagocytosis of human alveolar macrophages so as to play the anti-inflammation effect [29]. The reversible inhibition of cell activity enhanced cytotoxicity of NK cells was induced in vitro [30]. Nitrous oxide is also considered for promoted the postoperative tumor metastasis, while there is also the opposite view [31]. In vitro, sevoflurane can affect the NK cells which is to release active cytokines such as IL-1B and TNF-a. Isoflurane can increase the malignant potential of ovarian cancer cells by up regulate cell cycle, promoting cell proliferation and angiogenesis [32]. Another study showed that sevoflurane is better in

*Corresponding author: Qingxiu Wang, Department of Anesthesiology, Shanghai East Hospital, Tongji University School of Medicine, 150 Jimo Road, Shanghai 200120, China, Tel: 18721121605; E-mail: 18255354282@163.com

Received November 13, 2016; Accepted January 18, 2017; Published January 26, 2017

Citation: Zhou Y, Zhang H, Wang Q (2017) Relationship between Anesthesia and Tumor: Can the Anesthesia affect the Prognosis of the Tumor? Health Care Current Reviews 5: 184. doi: 10.4172/2375-4273.1000184

Copyright: $\odot 2017$ Zhou Y, et al. This is an open-access article distributed unde the terms of the Creative Commons Attribution License, which permits unrestricted use, distribution, and reproduction in any medium, provided the original author and source are credited. 
regulation of hepatocellular carcinoma in patients with peri-operative plasma inflammatory factors of information than isoflurane, so as to improve the prognosis of patients with tumor [33]. For a surgery for colorectal cancer study showed that sevoflurane compared with propofol total intravenous anesthesia to colorectal cancer five years survival rate of $4.7 \%$ and $5.6 \%$ growth [34]. Another study showed that patients with sevoflurane anesthesia and propofol anesthesia compared to reduce apoptosis of breast cancer cells in the breast cancer surgery [35]. Comparison of the propofol and isoflurane on the surgically induced that immune response effects of Th1/Th2 ratio in isoflurane group was found to decline markedly than propofol group [36-38]. It is indicating that compared with isoflurane, propofol is better to reduce the surgery stress which reduces the immune inhibition [39]. Patients with sevoflurane anesthesia can reduce the pro-inflammatory cytokines and matrix metalloproteinases [40]. Another clinical data showed that volatile anesthetics have exacerbated the effect of perioperative immunosuppression, but propofol have the opposite effect.

\section{Local Anesthetics}

Lidocaine has the membrane stabilizing effect [41]. The clinical concentrations can directly inhibit EGF receptors, and the proliferation of tumor cells, it can also reduce the invasive ability of tumor cells [42]. In vitro experiments found that ropivacaine can inhibit the growth of tumor cells.

\section{Other Drugs}

Dexmedetomidine can improve the patients undergoing radical operation for colon cancer cell immune function; reduce the probability of micro metastasis in blood circulation [43]. Another research showed patients with cellular immune transient suppression in breast cancer after radical surgery during general anesthesia, continuous intravenous infusion of dexmedetomidine can effectively inhibit perioperative stress and reduce the inhibition of cellular immune function after operation [44]. Juan has demonstrated that intraoperative dexamethasone administration to NSCLC patients was not associated with a significant impact on recurrence-free survival and overall survival [45]. De Oliveira shows that there were no evidence for an association between perioperative systemic dexamethasone administration and ovarian cancer recurrence after primary cytoreductive surgery. Kervoëlen insisted dexamethasone is widely used in the treatment of multiple myeloma by its cytotoxic effect, while its cytotoxic effect has also reported, and at last they suggested that the effect of dexamethasone should be re-evaluated within molecular subgroups of myeloma patients to improve its efficacy and reduce its adverse effects [46,47].

\section{Selection of Anesthetic Techniques}

At present, the advantages of combined anesthesia are obviously, and its usage is gradually increasing in the clinical [48]. Studies have shown that general anesthesia combined with epidural anesthesia can significantly reduce the short-term recurrence and metastasis rate of breast cancer, and improve the survival rate of patients with short-term recurrence free metastasis [49]. Compared with simple general anesthesia, combined anesthesia, epidural or spinal anesthesia can reduce the postoperative immune suppression. Some studies point out that local anesthesia and regional anesthesia can reduce tumor metastasis and recurrence [50-52]. While another recent analysis showed that regional block anesthesia cannot improve the overall survival rate of patients with cancer. A study of anesthesia for colon cancer surgery shows that propofol intravenous anesthesia and thoracic epidural anesthesia compared with general anesthesia with sevoflurane could influence the colon cancer cells, from the colorectal cancer patients serum inhibited cell proliferation invasion and induced apoptosis effect than sevoflurane anesthesia [53-55]. The mechanism maybe that the anesthesia will affect serum micro environment which affects the transfer of tumor cell biology and cancer cells, but this result is due to anti-inflammatory and antitumor properties by the propofol and epidural anesthesia or lidocaine and ropivacaine induced anti-inflammatory, anti-cytotoxic and anti-proliferative effects are not sure.

\section{Conclusion}

There are various factors affect the immune function of the patients during perioperative period and it cannot be considered a single factor to the prognosis of the tumor. The prognosis of the tumor is longer follow-up time, the influence factors are too many, the evaluation standard is detailed, which requires us to invest more research in order to accurate experimental results. As an anesthesiologist, it is necessary for us to according to the immune status of the patients during perioperative period to select appropriate anesthesia methods and drugs, in order to maximize the long-term prognosis of patients with surgical procedures.

\section{References}

1. Tarver $T$ (2012) Cancer facts and figures, atlanta. GA: American Cancer Society 16: 366-367.

2. Cata JP, Bauer M, Sokari T, Ramirez MF, Mason D, et al. (2013) Effects of surgery, general anesthesia, and perioperative epidural analgesia on the immune function of patients with non-small cell lung cancer. J Clin Anesth 25 255-262.

3. Schreiber RD, Old LJ, Smyth MJ (2011) Cancer immunoediting: Integrating immunity's roles in cancer suppression and promotion. Science 331: 15651570.

4. Heaney A, Buggy DJ (2012) Can anaesthetic and analgesic techniques affect cancer recurrence or metastasis? Br J Anaesth 1: i17-17i28.

5. Biki B, Mascha E, Moriarty DC, Fitzpatrick JM, Sessler DI, et al. (2008) Anesthetic technique for radical prostatectomy surgery affects cancer recurrence: A retrospective analysis. Anesthesiology 109: 180-187.

6. Schlagenhauff B, Ellwanger U, Breuninger H (2000) Prognostic impact of the type of anaesthesia used during the excision of primary cutaneous melanoma. Melanoma Research 10: 165-169.

7. Rees M, Tekkis PP, Welsh FKS (2008) Evaluation of long-term survival after hepatic resection for metastatic colorectal cancer: A multifactorial model of 929 patients. Ann Surg 247: 125-135.

8. Vauthey JN, Klimstra D, Franceschi D, Tao Y, Fortner J, et al. (1995) Factors affecting long-term outcome after hepatic resection for hepatocellular carcinoma. Am J Surg 169: 28-35.

9. Mammoto T, Mukai M, Mammoto A, Yamanaka Y, Hayashi Y, et al. (2002) Intravenous anesthetic, propofol inhibits invasion of cancer cells. Cancer Lett 184: 165-170.

10. Kushida A, Inada T, Shingu K (2007) Enhancement of antitumor immunity after propofol treatment in mice. Immunopharmacol Immunotoxicol 29: 477-486.

11. Su Z, Hou XK, Wen Q P (2014) Propofol induces apoptosis of epithelial ovarian cancer cells by upregulation of microRNA let-7i expression. Eur J Gynaecol Oncol 35: 688-691.

12. Siddiqui RA, Zerouga M, Wu M, Castillo A, Harvey K, et al. (2005) Anticancer properties of propofol-docosahexaenoate and propofol-eicosapentaenoate on breast cancer cells. Breast Cancer Res 7: R645-654.

13. Melamed R, Bar-Yosef S, Shakhar G (2003) Suppression of natural killer cell activity and promotion of tumor metastasis by ketamine, thiopental, and halothane, but not by propofol: Mediating mechanisms and prophylactic measures. Anesth Analg 97: 1331-1339.

14. Huang H, Benzonana LL, Zhao H, Watts HR, Perry NJ, et al. (2014) Prostate cancer cell malignancy via modulation of HIF-1a pathway with isoflurane and propofol alone and in combination. Br J Cancer 111: 1338-1349. 
15. Mikawa K, Akamatsu H, Nishina K, Shiga M, Maekawa N, et al. (1998) Propofol inhibits human neutrophil functions. Anesth Analg 87: 695-700.

16. Inada T, Yamanouchi Y, Jomura S, Sakamoto S, Takahashi M, et al. (2004) Effect of propofol and isoflurane anaesthesia on the immune response to surgery. Anaesthesia 59: 954-959.

17. Kushida A, Inada T, Shingu K (2007) Enhancement of antitumor immunity after propofol treatment in mice. Immunopharmacol Immunotoxicol 29: 477-486.

18. Braun S, Gaza N, Werdehausen R, Hermanns H, Bauer I, et al. (2010) Ketamine induces apoptosis via the mitochondrial pathway in human lymphocytes and neuronal cells. Br J Anaesth 105: 347-354

19. Shavit Y, Lewis JW, Terman G W (1984) Opioid peptides mediate the suppressive effect of stress on natural killer cell cytotoxicity. Science 223: 188-

20. Sacerdote $P$ (2006) Opioids and the immune system. Palliat Med 20: 9-15.

21. Forget $P$, Collet $V$, Lavand'homme $P$, De Kock $M$ (2010) Does analgesia and condition influence immunity after surgery? Effects of fentanyl, ketamine and clonidine on natural killer activity at different ages. Eur J Anaesthesiol 27: 233 240.

22. Forget $P$, Collet V, Lavand'homme $P$, De Kock M (2010) Does analgesia and condition influence immunity after surgery? Effects of fentanyl, ketamine and clonidine on natural killer activity at different ages. Eur J Anaesthesiol 27: 233 240.

23. Koodie L, Ramakrishnan S, Roy S (2010) Morphine suppresses tumor angiogenesis through a HIF-1a/p38MAPK pathway. Am J Pathol 177: 984-997.

24. Martin JL, Charboneau R, Barke RA (2010) Chronic morphine treatment inhibits LPS-induced angiogenesis: Implications in wound healing. Cell Immunol 265 : $139-145$

25. Sacerdote P, Bianchi M, Gaspani L, Manfredi B, Maucione A, et al. (2000) The effects of tramadol and morphine on immune responses and pain after surgery in cancer patients. Anesth Analg 90: 1411-1414.

26. Gaspani L, Bianchi M, Limiroli E, Panerai AE, Sacerdote P (2002) The analgesic drug tramadol prevents the effect of surgery on natural killer cell activity and metastatic colonization in rats. J Neuroimmunol 129: 18-24

27. Wigmore T, Farquhar-Smith $P$ (2016) Opioids and cancer: Friend or foe? Curr Opin Support Palliat Care 10: 109-118.

28. Schneemilch CE, Schilling T, Bank U (2004) Effects of general anaesthesia on inflammation. Best Pract Res Clin Anaesthesiol 18: 493-507.

29. Mitsuhata H, Shimizu R, Yokoyama MM (1995) Suppressive effects of volatile anesthetics on cytokine release in human peripheral blood mononuclear cells. Int J Immunopharmacol 17: 529-534.

30. Kotani N, Hashimoto H, Sessler DI, Kikuchi A, Suzuki A, et al. (1998) Intraoperative modulation of alveolar macrophage function during isoflurane and propofol anesthesia. Anesthesiology 89: 1125-1132.

31. Nakamura Y, Yasuoka H, Tsujimoto M, Yoshidome K, Nakahara M, et al. (2006) Nitric oxide in breast cancer: induction of vascular endothelial growth factor-C and correlation with metastasis and poor prognosis. Clin Cancer Res 12: 12011207.

32. Fleischmann E, Marschalek C, Schlemitz K (2009) Nitrous oxide may not increase the risk of cancer recurrence after colorectal surgery: A follow-up of a randomized controlled trial. BMC anesthesiology 9: 1

33. Luo X, Zhao H, Hennah L, Ning J, Liu J, et al. (2015) Impact of isoflurane on malignant capability of ovarian cancer in vitro. Br J Anaesth 114: 831-839.

34. Bedirli N, Ofluoglu E, Kerem M, Utebey G, Alper M, et al. (2008) Hepatic energy metabolism and the differential protective effects of sevoflurane and isoflurane anesthesia in a rat hepatic ischemia-reperfusion injury model. Anesth Analg 106: 830-837.

35. Enlund M, Berglund A Andreasson K (2014) The choice of anaesthetic sevoflurane or propofol and outcome from cancer surgery: A retrospective analysis. Ups J Med Sci 119: 251-261

36. Deegan CA, Murray D, Doran P, Moriarty DC, Sessler DI, et al. (2010) Anesthetic technique and the cytokine and matrix metalloproteinase response to primary breast cancer surgery. Reg Anesth Pain Med 35: 490-495.

37. Inada T, Yamanouchi Y, Jomura S, Sakamoto S, Takahashi M, et al. (2004)
Effect of propofol and isoflurane anaesthesia on the immune response to surgery. Anaesthesia 59: 954-959.

38. Ahn HJ, Chung SK, Dhong HJ (2008) Comparison of surgical conditions during propofol or sevoflurane anaesthesia for endoscopic sinus surgery. $\mathrm{Br} \mathrm{J}$ Anaesth 100: $50-54$.

39. Neeman E, Ben-Eliyahu S (2013) Surgery and stress promote cance metastasis: New outlooks on perioperative mediating mechanisms and immune involvement. Brain Behav Immun 30: S32-S40.

40. Deegan CA, Murray D, Doran P, Moriarty DC, Sessler DI, et al. (2010) Anesthetic technique and the cytokine and matrix metalloproteinase response to primary breast cancer surgery. Reg Anesth Pain Med 35: 490-495.

41. Snyder GL, Greenberg S (2010) Effect of anaesthetic technique and other perioperative factors on cancer recurrence. $\mathrm{Br} J$ Anaesth 105: 106-115.

42. Mammoto T, Higashiyama S, Mukai M, Mammoto A, Ayaki M, et al. (2002) Infiltration anesthetic lidocaine inhibits cancer cell invasion by modulating ectodomain shedding of heparin-binding epidermal growth factor-like growth factor (HB-EGF). J Cell Physiol 192: 351-358.

43. Mammoto T, Higashiyama S, Mukai M, Mammoto A, Ayaki M, et al. (2002) Infiltration anesthetic lidocaine inhibits cancer cell invasion by modulating ectodomain shedding of heparin-binding epidermal growth factor-like growth factor (HB-EGF). J Cell Physiol 192: 351-358.

44. Martinsson T (1999) Ropivacaine inhibits serum-induced proliferation of colon adenocarcinoma cells in vitro. J Pharmacol Exp Ther 288: 660-664.

45. Liang $\mathrm{H}$, Liu $\mathrm{H}$, Wang $\mathrm{H}$ (2012) Effects of dexmedetomidine on colon cancer patients undergoing radical surgery perioperative cellular immune function and blood circulation micrometastases. Chinese Journal of Anesthesiology 32 1165-1168.

46. Fu G, Xu X, Zhou L, Gong L, Li X, et al. (2014) Dexmedetomidine on breast cancer patients perioperative effects of $T$ lymphocyte subsets in. Chinese Journal of Experimental Surgery 31: 944-946.

47. Cata JP, Jones J, Sepesi B, Mehran RJ, Rodriguez-Restrepo A, et al. (2016) Lack of association between dexamethasone and long-term survival after nonsmall cell lung cancer surgery. J Cardiothorac Vasc Anesth 30: 930-935

48. De Oliveira GS Jr, McCarthy R, Turan A, Schink JC, Fitzgerald PC, et al. (2014) Is dexamethasone associated with recurrence of ovarian cancer? Anesth Analg 118: $1213-1218$

49. Kervoelen C, Menoret E, Gomez-Bougie, P (2015) Dexamethasone-induced cell death is restricted to specific molecular subgroups of multiple myeloma. Oncotarget. 6: 26922-26934.

50. Exadaktylos AK, Buggy DJ, Moriarty DC (2006) Can anesthetic technique for primary breast cancer surgery affects recurrence or metastasis? Anesthesiology 105: 660-664.

51. Mrakovcic-Sutic I, Bacic D, Golubovic S (2011) Cross-talk between NKT and regulatory $T$ cells (Tregs) in modulation of immune response in patients with colorectal cancer following different pain management techniques. Coll Antropol 35: 57-60.

2. Sessler DI, Ben-Eliyahu S, Mascha EJ (2008) Can regional analgesia reduce the risk of recurrence after breast cancer? Methodology of a multicenter randomized trial. Contemp Clin Trials 29: 517-526.

53. Gottschalk A, Ford JG, Regelin CC, You J, Mascha EJ, et al. (2010) Association between epidural analgesia and cancer recurrence after colorectal cancer surgery. Anesthesiology 113: 27-34.

54. Myles PS, Peyton P, Silbert B, Hunt J, Rigg JR, et al. (2011) Perioperative epidural analgesia for major abdominal surgery for cancer and recurrence-free survival: Randomised trial. BMJ 342: d1491.

55. Scott NB, Turfrey DJ, Ray DAA, Nzewi O, Sutcliffe NP, et al. (2001)A prospective randomized study of the potential benefits of thoracic epidural anesthesia and analgesia in patients undergoing coronary artery bypass grafting. Anesth Analg, 93: 528-535. 